\title{
Internet y la ciudad ${ }^{*}$
}

\section{Florian Forestier**}

Traducción del francés al español de Jorge Márquez Valderrama***

\begin{abstract}
La metáfora urbana es pertinente y fecunda para comprender qué es el ciberespacio. Concretamente, se observa, además, una hibridación de esos dos espacios: a medida que la Web se inscribe cada vez más estrechamente en nuestra práctica cotidiana de la ciudad, esta última adquiere por ello una profundidad nueva, a la vez cognitiva y vivida.
\end{abstract}

Quisiéramos mostrar aquí el interés que puede haber al considerar Internet como un espacio, y más específicamente como un espacio urbanizado. Por varias razones, la metáfora arquitectural y urbana es fecunda. Permite caracterizar una red estructurada sin que esa estructura sea impuesta a priori, y comprender de qué manera esa estructura puede integrar el azar, volverlo creador, desarrollar una serendipia, esa facultad de encontrar lo que no se busca. Por estas dos razones, es interesante considerar Internet a través del prisma de la ciudad: Internet no es un puro caos, un puro espacio de inmanencia plano, es un espacio estructurado, en el cual son posibles encuentros y creación. Esas posibilidades se actualizan a medida que Internet se inserta de manera más fluida y continua en nuestras prácticas cotidianas. Desde esta óptica, nos interesamos en las hibridaciones entre el espacio de la Web y el espacio urbano, en la manera como el desarrollo de la Web de los objetos cambia el sentido de Internet, en los ires y venires cada vez más frecuentes y ricos que se instauran entre Internet y el espacio urbano.

Médium, transmettre pour innover. $\mathrm{N}^{\circ}$. 36, juillet-août, 2013: 110-121. Traducción realizada en Medellín, 19 de agosto de 2015.

** Doctor en Filosofía, es investigador asociado a la Universidad Paris IV-Sorbonne y encargado en la colección en la BNF. Últimos libros: Le réel et le transcendantal: enquête sur les fondements spéculatifs de la phénoménologie et le statut du "phénoménologique". Thèse de doctorat en philosophie. Université Toulouse le Mirail - Toulouse II, 2011. La Phénomenologie génétique de Marc Richir, Springer, Suiza, 2015.

*** Profesor titular de la Universidad Nacional de Colombia, para el seminario "Medios, realidad y representación en democracia". Correo electrónico: jmarquez@unal.edu.co 
Esas modificaciones de los comportamientos y prácticas implican al mismo tiempo mutaciones del estatuto de lo que ocurre en Internet. La práctica de almacenamiento de la Web nos permitirá poner en paralelo la patrimonialización del espacio urbano y del espacio de la Web para intentar comprender mejor mediante qué estrategias se intenta, a pesar de la disolución de las normas y referencias fijas, de inscribir a la vez ciertos límites y el espesor temporal que caracteriza el espacio como espacio habitado, humanizado.

\section{La metáfora urbana}

Al menos en dos planos, la ciudad es un modelo fecundo. Primero, porque constituye un ejemplo de sistema complejo y evolutivo "no limitado"; segundo, porque permite pensar la realización de horizontes de sentido en el seno de un espacio generador.

La metáfora urbana es una forma de pensar, sin reducirla, la complejidad de los universos de la información, pero también de comprender que esa complejidad se traduce en una estructuración. Ya el término "arquitectura" es utilizado de manera corriente en informática para designar la estructura general de un sistema de información; se habla de arquitectura logicielle, de arquitectura de las informaciones, de arquitectura material, etc. De ahora en adelante, en un momento en que toda institución es susceptible de ser asociada a un sistema de información, la evolución de las instituciones (reagrupamientos y fusiones, adquisiciones, acuerdos estratégicos, reorganización, exteriorización) exige una adaptación de sus aplicaciones informáticas. En esa perspectiva, la urbanización de los sistemas de información consiste en hacer evolucionar sus funciones de concierto, favoreciendo su evolución y su "interoperabilidad». En este sentido, el sistema de información puede ser comparado con un barrio de una ciudad: si este último está bien urbanizado. Un edificio puede ser reemplazado por otro sin fragilizar el tejido urbano. De la misma manera, un sistema de información estará bien urbanizado si una aplicación puede reemplazar a otra sin que se requiera una refundición de todo el sistema ni desestabilizar su funcionamiento.

El urbanismo es también una manera interesante de abordar el espacio común en tanto que él está habitado, que ocurren cosas en él, que algo nuevo cobra forma ahí: un modo de estar juntos que insiste en el poder creador del azar, del encuentro, en un sentido latente, potencial, rozado, propuesto sin ser impuesto. En el sentido del urbanismo, la ciudad no es un magma, pero tampoco es un espacio fijado de una vez por todas: ella vive de límites, de cambios de atmósfera, de gradaciones, de pasos, pero no instituye una manera definitiva y ceremonial de referirse a ella misma. Para Benoît Goetz ${ }^{1}$, la arquitectura con-

\footnotetext{
La dislocation, Architecture et philosophie.
} 
temporánea es trabajada por este horizonte de urbanismo. Ella es configuración de horizontes capaces de hacer vivir el sentido que se intercambia. Goetz desarrolla con esos fines el concepto de esplaza: el esplaza " deja sitio " pues, dice él, la arquitectura comienza cuando los muros se abren. La espacialidad no remite solamente al espacio físico, sino también a la distancia, esta reserva de implícito, de latencia, ese entre-nosotros que hace que vivamos en comunidad. En tal perspectiva, pensar la Web como espacio urbanizado permite comprender lo que hace de ella (o lo que le falta para hacer de ella) un espacio habitado, proponiendo lugares en los cuales un se encuentra con otros, punto de tránsito, circulaciones, una sociabilidad ${ }^{2}$.

\section{Dos espacios que se hibridan}

La evolución técnica contribuye precisamente a reforzar los aspectos concretos de la urbanización de Internet. Por la evolución de sus funciones y de sus modos de acceso, Internet deja de ser un espacio cerrado al cual se accede según modalidades para volverse (en su casa), posturas (sentado ante el computador), circunstancias (casi siempre solo) específicas que lo determinan. Uno se conecta sin importar el cuándo, el lugar, con fines cada vez más prácticos, cada vez más integrados a nuestra existencia cotidiana, en todas las circunstancias. Internet mismo responde inmediatamente, en tiempo real, a los requerimientos que se le lanzan (podemos encontrarnos en directo pasando por una conexión). De esta manera, Internet se vuelve una extensión y un enriquecimiento de la ciudad y de las prácticas de las cuales ella es el teatro.

Como lo subraya Hubert Guillaud ${ }^{3}$, numerosas aplicaciones permiten revelar lo real en lo digital. Los modelos virtuales del espacio físico tienen que ver ante todo con envites industriales (modelos de máquinas, objetos industriales, fábricas, etc.); actualmente, están ligados a prácticas más corrientes. La convergencia de sistemas de información geográfica (GPS y otros) y de redes sociales, generalizando el funcionamiento síncrono de tales aplicaciones da a la cartografía una función práctica y plástica. Nos percibimos unos a otros in situ, a partir de mapas interactivos y compartidos, sobre los cuales cada quien deja huellas al señalar su paso, al escribir sus impresiones, al añadir sus propias fotos, que vienen a inscribirse virtualmente en un lugar. Los puntos de entrada, de acceso, de lectura de la realidad se multiplican: el enriquecimiento de los modos de acceso al mundo digital requiere de formas de indexación cada vez complejas, y un modo cada vez más elaborado de circulación en el seno de esas indexaciones. Los motores de búsqueda operan en adelante tanto sobre los

\footnotetext{
2 Sobre este punto, se puede consultar nuestro artículo: "Remarques sur le schème spatial", Implications philosophiques, 2013.

3 http://www.scribd.com/doc/42370086/Besoin-d-hybrides-Hubert-Guillaud
} 
sonidos como sobre las imágenes. El desarrollo de la Web semántica acarrea igualmente un enriquecimiento de los usos y de las prácticas de los internautas. Y el desarrollo de una informática local (localizada) acentúa aún más la territorialización de Internet.

Para caracterizar esta "profundidad compartida", Adam Greenfield desarrolló el concepto de Long Here: cada lugar adquiere una dimensión, una profundidad histórica (la historia de un inmueble, de una ciudad...), asociadas a sus coordenadas de pura localización. Así, uno puede, de alguna manera, encontrarse "entre" quienes han frecuentado tal lugar en tales circunstancias. El concepto correlativo de Big Now designa, por su parte, el aflujo de datos que nos asaltan en tiempo real (simultáneamente) en un lugar, datos susceptibles de ser emitidos mediante los objetos urbanos que encontramos. Al facilitar las condiciones de uso, el desarrollo de lo que se llama el Internet de los objetos refuerza, pues, esta hibridación. La tecnología se inscribe así, "sin costuras", en las prácticas en cuyo seno ella se hace olvidar. La cuestión de la ergonomía de las interfaces de consulta es central: la mayor o menor flexibilidad de las posiciones, disposiciones, formas de concentración exigidas para acceder a Internet juega un papel determinante para esta integración. La oculometría y el estudio de las posturas son campos de investigación íntegros para los actores del mundo digital. El éxito de ciertas empresas proviene en gran parte de que ellas han dejado de pensar sus productos como objetos rígidos que imponen un espacio al cual el usuario solo tenía que adaptarse, para concebirlos a partir de sus funciones en prolongación de hábitos corporales y cognitivos. Esta cuestión es particularmente bien ilustrada por el caso del desarrollo del libro electrónico, habiéndose desarrollado precisamente, no solamente como un vector de informaciones, sino como una forma simbólica que facilita cierto modo de apertura al sentido ${ }^{4}$, y adaptado a la morfología humana. El perfeccionamiento de formas elaboradas de papel electrónico (no retro iluminado) modifica así las perspectivas llevadas sobre el libro digital, que puede precisamente volverse digital y seguir siendo un libro, al enriquecer y retomar la forma libre.

Lo que tiene lugar es precisamente una hibridación, no solamente de Internet, sino de lo virtual en general y de (por así decirlo) lo real que tiene lugar. Por una parte, se interactúa con el entorno físico como si se tratara de un entorno virtual, cliqueando, navegando, y, por otra parte, lo digital viene por sí mismo a inscribirse en el espacio real, en cuyo seno se le encuentra, como se encuentran los otros objetos. Según Hubert Guillaud, esta hibridación tiene que ver con un verdadero proyecto de industria, pues, contrariamente a lo que deja pensar el término desmaterialización, la infraestructura industrial de producción y de man4 A este respecto, me permito remitir al lector a mi texto "Lıelargissement de lıespace du livre" (Argus, vol. 40,
$\mathrm{n} .{ }^{\circ}$ 2, dec. 2011. http://revueargus.org/?p=628). 
tenimiento de tales interfaces (no se trata aquí de objetos, sino de estructuras colectivas) es extremadamente pesada. Esa pesantez industrial implícita invita, por otra parte, a conservar cierta prudencia sobre las realizaciones que se harán efectivamente, por fuera de lo anecdótico y de lo experimental. Se recordará a este respecto que, a pesar de los numerosos progresos técnicos, el mercado de la domótica ${ }^{5}$ siguió estancado desde los años 1980, y que las construcciones de ciudades inteligentes, como el proyecto saudí de la King Abdullah Economic City, requerirá de decenas de años de amortización.

De todas maneras, si concebir la ciudad sobre el modelo de la web puede parecer actualmente quimérico, los desarrollos que hemos evocado dan testimonio real de una interpenetración creciente entre los espacios urbanos y los digitales, que se traduce por un "espesamiento" de Internet.

\section{Depósito legal: la patrimonialización de Internet}

La evolución de las prácticas ligadas a Internet invita a enfocarse sobre el estatuto -legal y simbólico- que hay que asignar a ese Internet espesado y densificado. Un acontecimiento en el ciberespacio ¿es la misma cosa que un acontecimiento en el mundo real? Para tomar un ejemplo extremo: es sabido que apoyar sobre un botón o asaltar un banco, pueden tener el mismo efecto y la misma apreciación legal, pero es difícil -y sin duda lo seguirá siendo por mucho tiempo- que el envite se manifieste con la misma claridad y la misma evidencia en las dos situaciones. Lo que pasa en Internet, lo que se hace allí, lo que allí se crea existe con su densidad propia, engendra o moviliza una historia, tiene un peso que hay que considerar. El archivo de la web es un buen ejemplo para interrogarse sobre ese espesor simbólico del espacio de Internet. Instituido en Francia en agosto $2006^{6}$, el almacenamiento en la web prolonga en apariencia la ampliación sucesiva de los dominios concernidos por el depósito legal: libros, estampas, planos y cartas, partituras musicales, fuentes de fotografías, artes gráficas de todo tipo, libros y periódicos, afiches y prospectos, bandas y discos, películas y documentos multimedia. Por tanto, él hace evolucionar considerablemente el sentido mismo del depósito legal al interrogar la relación de Internet con el territorio, en sus diversas acepciones, geográficas, políticas e incluso simbólicas. Como lo subraya Gildas Illien: "Las bibliotecas nacionales son herederas del concepto de Estado-nación, que presupone cierta unidad entre una cultura, una lengua, un territorio, soportes de publicación.

5 Se llama "domótica" al conjunto de sistemas capaces de automatizar una vivienda, aportando servicios de gestión energética, seguridad, bienestar y comunicación, y que pueden estar integrados por medio de redes interiores y exteriores de comunicación, cableadas o inalámbricas, y cuyo control goza de cierta ubicuidad, desde dentro y fuera del hogar. Se podría definir como la integración de la tecnología en el diseño inteligente de un recinto cerrado. (t.)

6 http://www.bnf.fr/documents/bibliographie_dl_Web.pdf 
¿Cómo pueden ellas pretender conservar un media cuyos contenidos están masivamente desmaterializados y son compartidos por fuera de las fronteras del Estado?"7. En efecto, la colecta del depósito legal de la Web está muy ligada a un territorio: tiene que ver ahí todo nombre de dominio en .fr, por una parte; y por otra, todo nombre de dominio producido por alguien domiciliado en el territorio francés. La colecta invita desde entonces a redefinir líneas territoriales en la Web. En la práctica, la "cosecha" se efectúa, por una parte, al orientar los robots hacia sucedáneos de territorios, que son así calificados sin ser todavía explorados ni colonizados y, por otra parte, al apoyarse en zonas especificadas, núcleos temáticos explorados más finamente y constituidos en corpus (blogs, sitios políticos o culturales, etc.). La voluntad documental se expresa, así, en niveles diferentes: por un lado, constituye corpus, o sea colecciones, como resultado de una selección razonada; por otro lado, patrimonializa espacios cada vez más vastos sin pronunciarse sobre el valor de lo que se encuentra allí, pero abriéndolos a la exploración.

El estatuto de tales archivos es problemático y quizá ni siquiera tiene que ver con lo que es un archivo en sentido clásico. Efectivamente, en la web lo escrito tiene en gran parte estatuto oral, de conversaciones registradas en vivo (foros, blogs, twits, que igualmente es necesario archivar), de anuncios (carteles), indicaciones incomprensibles si se las priva de su contexto. Internet contiene al mismo tiempo estructuras perennes como informaciones transitorias: no todo puede ser considerado como publicado en el sentido clásico. Un investigador, interrogado en el marco de una encuesta adelantada por Gildas Illien y Philippe Chevalier sobre los usos posibles del archivo de la web, explica bien que "Internet tiene que ver [...] mucho menos con la publicación y con fuentes que con un grado de realidad", lo que subraya igualmente Clément Oury, actualmente responsable del depósito legal de la web en la Biblioteca Nacional de Francia. $\mathrm{El}$ archivamiento de la web se emparienta con una arqueología. Como una ciudad, Internet presenta diferentes estratos cronológicos que el almacenamiento exhuma. La metáfora arqueológica, como testimonia la encuesta evocada más arriba, es utilizada espontáneamente por los investigadores que trabajan sobre la web archivada. "Un arqueólogo del tiempo futuro, en lugar de ir a trabajar en estratos de tierras, tendrá interés en ir a trabajar sobre Internet y sobre los archivos Internet, pues allí encontrará todo lo que un arqueólogo puede buscar en la tierra: pequeños restos, tiestos, eso está muy bien", anota un investigador interrogado.

A partir de ahí se ganará al considerar las reflexiones sobre la patrimonialización del espacio urbano para comprender mejor lo que revela la patrimonia-

7 Gildas Illien, "Une histoire politique de liarchivage du Web", Bulletin des Bibliothèques de France, 2011, nº 2, p. 60-68. 
lización de Internet. Como lo precisa Michel Melot ${ }^{8}$ a propósito del Inventario general, la noción de patrimonio cultural traduce una transformación del espacio: permite conservar abierto un espacio cuyas coordenadas ya no son fijas, inscribir en él la dimensión del tiempo, dejar abierta la pregunta por el valor, pues esa pregunta habita la comunidad que ha producido ese valor. La comunidad la requiere ${ }^{9}$. De la misma manera, la práctica del depósito legal de la web concurre para reconocer a la web como un espacio común en el cual se vive, se intercambia, se dan encuentros, se aparece y se comparece, un espacio abierto para esa articulación arquitectural y simbólica que hace de la web un lugar de circulación del sentido. La práctica del depósito legal de la web da testimonio y reconoce institucionalmente que lo que ocurre en Internet existe, que incluso puede haber allí historia, creación, aventura, obra sobre Internet.

Concluiremos interrogando las consecuencias posibles de la evolución hacia lo que se llama la web 3.0, caracterizada, en particular, por la personalización de las interfaces. ¿Esta individualización va a enriquecer o, al contrario, va a disipar la dimensión espacial y urbana? ¿Va a desembocar en burbujas o en la explosión de las burbujas? La personalización de las interfaces puede tener dos efectos: puede acrecentar mi capacidad de escrutar prolongando, anticipando, amplificando mi curiosidad, pero también puede conducir a un narcisismo absoluto. Puede entabicar la ciudad o reforzar los lazos que me atan a ella y hacen de ella un lugar que habito, donde me proyecto, me construyo; puede ofrecer más grano o disipar toda aspereza, incitar a cada vez más invención o atenuar toda curiosidad. Esa evolución ya cuestiona en todo caso la práctica del almacenamiento en la web. Técnicamente, las interfaces no son cosechables, y las partes en línea, multi-jugadores, por el momento, solo son colectadas de manera indirecta, mediante el registro por filmación de sesiones o por almacenamiento de lo que ya está constituido como archivo. Pero ¿qué estatuto dar a esos espacios transitorios, co-construidos, movedizos, en una ciudad donde la mayoría de las casas serían móviles, una ciudad que ya no sería una construcción en el sentido tradicional, sino un encajamiento de piezas libres y superponibles?

8 Michel Melot, "Le patrimoine illimité", Médium, n. ${ }^{\circ}$ 24-25, juillet-décembre 2010, pp. 277-288.

9 Sobre este punto, se podrá consultar nuestra entrevista con Michel Melot a propósito de su obra Miralibia. Essai sur linventaire général du patrimoine culturel, Gallimard, 2012 ; legible en el sitio Actu.philosophia: http://www.actu-philosophia.com/spip.php?article426. 